\title{
Development of a multi-year climate prediction model
}

\author{
WJR Alexander \\ Department of Civil and Biosystems Engineering, University of Pretoria, Pretoria 0002, South Africa
}

\begin{abstract}
The available water resources in Southern Africa are rapidly approaching the limits of economic exploitation. The situation is compounded by claims that global warming will have a serious adverse effect on future water supplies. There was therefore an urgent need to characterise the numerical properties of the hydrometeorological processes in such a way that the effects of global warming, if any, could be evaluated and accommodated. Other than increases in both areal rainfall and open water surface evaporation, no other changes were detected, that could be attributed to climate change arising from human activities. Nor is there evidence to support the view that such changes are likely to occur within the normal planning horizon of the next 30 years. A climate prediction model was developed based on the statistically significant 21-year periodicity in the hydrometeorological processes, and its direct association with corresponding periodicity in solar activity.
\end{abstract}

Keywords: climate change, climate model, water resources

\section{Introduction}

The Commission of Enquiry into Water Matters was appointed by the State President of South Africa on 1 July 1966. The Commission's report RP 34/1970 was published in 1970. The report led to the establishment of the Water Research Commission (WRC). One of the recommendations made in the report was:

Long range weather forecasts, if reliable, can provide valuable information for the operation of storage works and for planning of irrigation programmes and can aid in improving the efficiency of water utilisation. The Commission recommends, therefore, that thorough investigations and research be promoted by the Weather Bureau and other interested organisations into the possibilities of making reliable longrange weather forecasts up to a year or more ahead.

Thirty years have passed and still no such methods have been developed, while the need for them has become critical. It was with this urgent need in mind that studies were commenced some three years ago. Right from the beginning, it was obvious that the task would be difficult, otherwise a forecasting method would have been developed long ago. It was equally obvious that the perfect method would not be achievable. The objective was to develop a general model that would be of immediate use as well as provide the basis for future applications, particularly the incorporation of the effects of climate change, should such effects be demonstrated numerically with an acceptable degree of confidence.

Claims have been made that human activity has accelerated global warming, and this in turn will result in increased variability in the hydrometeorological processes, specifically rainfall and river flow, which together pose a threat to water supplies (Intergovernmental Panel on Climate Change, 2001). While there have been a number of publications addressing the

II: +2712 991-3151; fax: +2712 991-8473;

e-mail: alexwjr@iafrica.com

Received 10 September 2004; accepted in revised form 24 January 2005. hydrological aspects of climate change (Paoli, 1994; Abu-Zeid et al., 1992; Fantechi et al., 1991 and Duplessy et al., 1990 for example), most of them start with the assumption that climate change will have an adverse effect on the hydrological processes, without assessing the validity of the claims or quantifying the hydrological responses to the degree required by water resource planners. These claims will remain suspect until quantifiable linkages can be found between atmospheric processes and hydrometeorological responses. An ultra-cautious approach was adopted in the analyses in view of the high level of international controversy that exists.

\section{Data}

The largest and most comprehensive hydrometeorological database yet assembled in South Africa was studied. It consisted of 11804 years of data from 183 sites and 7 different hydrometeorological processes. Details are given in Table 1.

\begin{tabular}{|l|l|c|c|}
\hline \multicolumn{4}{|c|}{ TABLE 1 } \\
\hline Set & Process & Stations & Years \\
\hline 1 & Water surface evaporation & 20 & 1180 \\
\hline 2 & Concurrent rainfall & 20 & 1180 \\
\hline 3 & District rainfall & 93 & 7141 \\
\hline 4 & River flow & 28 & 1877 \\
\hline 5 & Flood peak maxima & 17 & 1235 \\
\hline 6 & Groundwater & 4 & 312 \\
\hline 7 & Southern oscillation index & 1 & 114 \\
\hline & TOTAL & 183 & 11804 \\
\hline
\end{tabular}

The sites were selected on the basis of their geographical representativeness and long, reliable records. All except two of the records (Southern Oscillation Index and Zambezi River flow) were extracted from official databases operated by the South African Weather Service (SAWS) and the Department of Water Affairs and Forestry (DWAF). Other than minor patching of missing data, the data were not smoothed, filtered or in any way manipulated before or during the analyses. 


\section{Analytical procedure}

The international opinion as expressed in the Intergovernmental Panel on Climate Change (IPCC) (2001) documents is that global warming has been present for many decades and even centuries in some cases, and is increasing. This being so, the consequences should already be detectable in long hydrometeorological records, many of which exceed 70 years in length, and some observations extend back to the mid 1800s.

The first step was to establish a baseline condition for the annual data from each site. Two fundamentally different approaches have been used for this purpose in the past. The approach currently used by engineering hydrologists is to examine the variability about a constant mean equal to the record mean. The simulation model had to be such that it could be used to develop equally likely sequences using Monte Carlo methods. The methodology is described by Basson et al. (1994). They considered that the essence was to concentrate on the selection and estimation of a suitable marginal distribution function and not relegate it to a secondary role at the expense of undertaking time series analysis.

In contrast, the methodology most used in the natural sciences is to apply spectral analysis methods to the data sequence without separating the mean from the variability about the mean. This is a curve-fitting procedure where the time series are assumed to consist of a combination of cycles of differing phase, magnitude and periods. Users of the method then erroneously concluded that this compound cyclicity is real whereas it is an artefact of the procedure. This is a serious misinterpretation.

As will be shown, neither method could be used in the present analyses where an altogether different route was followed. It was appreciated from the start that the identification of signals that could be directly attributed to climatic variability would be difficult because of the high natural variability of the processes. In essence, the search was for signals that were common to all data sets of a process, as well as all of the different processes. Another requirement was that the signals had to be concurrent, i.e. they occurred simultaneously in all data sets of all the processes examined. While this was a tall order, even faint concurrent signals that were common to most data sets and most processes would be convincing.

Mathematical/statistical analyses were deliberately avoided as these are hypothesis- testing procedures where the problem was not in testing the hypotheses but in identifying them. Consequently graphical procedures were used. These are far more effective in this situation.

The first process analysed was areal rainfall. The South African Weather Bureau, now South African Weather Service, divided South Africa into 93 rainfall districts, and published data for each district (Weather Bureau, 1972). The analyses showed a sustained increase in the rainfall over South Africa during the 78-year period of record from October 1922 to September 2000 The mean annual rainfall over South Africa increased from 497 $\mathrm{mm}$ to $543 \mathrm{~mm}$ during this period. The following is a summary of the changes.

$\begin{array}{ll}\text { Decrease } & 8 \text { districts } \\ \text { Increase } 1 \text { to } 19 \mathrm{~mm} & 6 \text { districts } \\ \text { Increase } 20 \text { to } 70 \mathrm{~mm} & 52 \text { districts } \\ \text { Increase greater than } 70 \mathrm{~mm} & \begin{array}{l}15 \text { districts } \\ 81 \text { districts with complete } \\ \text { TOTAL }\end{array} \\ & \text { records }\end{array}$

This increase was well substantiated by other analyses and is in accordance with IPCC projections. This is also similar in magnitude and direction to that observed by Gleick (2000), who reported that the average precipitation over the contiguous USA has increased by about $10 \%$ since 1910, and that the United States has, on average, warmed by two-thirds of a degree Celsius since 1900. This not only confirms the credibility of the methodology used here, but also demonstrates that a quantifiable linkage exists between global warming (from whatever cause) and the increase in rainfall over South Africa. Open water surface evaporation also showed an increase.

The next issue was whether a similar linkage could be found between global warming, river flow, and flood peak maxima. This is inherently more difficult because of the large natural variability of the data. It is also complicated because river flow is increasingly being influenced by upstream withdrawals and catchment utilisation, particularly in the presence of high exploitation of the water resources. In an earlier presentation (Alexander, 2002b) it was shown that the natural variability and complexity in the flood magnitude-frequency relationship was so high that the effects of climate change, if any, would be undetectable against the background of natural variability. Unlike rainfall where an increase was found, there was no detectable evidence of any changes in river flow and floods that could be ascribed to global warming.

This conclusion was confirmed by analyses of historical data prior to the commencement of routine observations, which showed that a number of floods of the mid-1800s exceeded any subsequent floods recorded at the same sites. The years in which they occurred showed no progressive pattern that could be attributed to climate change. These observations and the calibration methods were checked and found to be reliable.

\section{Alternating wet and dry sequences in rainfall and river flow}

The claim that global warming will result in increasing threats to water supplies (IPCC, 2001) was investigated. This claim is based on the assumption that global warming will result in an increase in the variability of river flow. Both climatologists and hydrologists have difficulty in testing the validity of this conclusion. Climatologists have not been able to provide any numerical quantification to support their views. Without this quantification, hydrologists are unable to evaluate its validity or importance.

Once again, there is an urgent need to provide a numerical linkage between multi-year atmospheric processes and hydrometeorological responses. The magnitude-frequency relationship of annual rainfall, river flow and flood peaks, is two-dimensional, but droughts that pose a threat to water supplies have another two dimensions - area and duration. The rainfall depth-areaduration-frequency relationship cannot be determined theoretically (Alexander 2001). In this paper the dimension of area is omitted from further consideration as the additional dimension makes the analyses intractable.

The most important characteristic of a drought is its duration. This involves a study of annual sequences of below-average rainfall in the case of agricultural droughts or below-average river flow in the case of water supply droughts. The principles are the same. Use is made of the terms wet and dry sequences to cover both rainfall and river flow.

There are many examples in the literature of the presence of unnatural (in the statistical sense) groupings of annual wet and dry sequences. The earliest is the biblical reference to Joseph's interpretation of the Pharaoh's dream. "Behold, there came seven years of great plenty throughout the land of Egypt - and there shall arise after them seven years of famine" (Genesis, 


\begin{tabular}{|l|c|c|c|c|c|c|}
\hline \multicolumn{7}{|c|}{ TABLE 2 } \\
\hline Procesens & $\begin{array}{c}\text { No of 21-year periodicity in hydrometeorological data } \\
\text { sites }\end{array}$ & $\begin{array}{c}\text { Record } \\
\text { years }\end{array}$ & & \multicolumn{5}{c|}{ Periodicity } \\
\cline { 5 - 8 } & & & $95 \%$ & Present & None & $\begin{array}{c}\text { Not determi- } \\
\text { nable }\end{array}$ \\
\hline Evaporation & 20 & 1180 & 0 & 0 & 20 & 0 \\
\hline Rainfall & 93 & 7141 & 18 & 67 & 8 & 0 \\
\hline River flow & 28 & 1877 & 7 & 12 & 5 & 4 \\
\hline $\begin{array}{l}\text { Flood peak } \\
\text { maxima }\end{array}$ & 17 & 1235 & 4 & 7 & 2 & 4 \\
\hline
\end{tabular}

\begin{tabular}{|l|c|c|c|c|}
\hline \multicolumn{5}{|c|}{$\begin{array}{c}\text { TABLE 3 } \\
\text { wydrological and meteorological records that exhibit sudden reversals } \\
\text { within one or two years of 1912, 1933, 1954, 1974 and 1995 }\end{array}$} \\
\hline Process & $\begin{array}{c}\text { Number of } \\
\text { stations }\end{array}$ & $\begin{array}{c}\text { Number } \\
\text { of years }\end{array}$ & $\begin{array}{c}\text { Number of } \\
\text { stations } \\
\text { where re- } \\
\text { versals are } \\
\text { present }\end{array}$ & $\begin{array}{c}\text { Number of these } \\
\text { reversals that are } \\
\text { statistically sig- } \\
\text { nificant at the 95\% } \\
\text { level }\end{array}$ \\
\hline $\begin{array}{l}\text { Open water surface } \\
\text { evaporation }\end{array}$ & 20 & 1180 & 0 & 0 \\
\hline District rainfall & 93 & 7141 & 56 & 18 \\
\hline River flow & 28 & 1877 & 22 & 7 \\
\hline Flood peak maxima & 17 & 1235 & 14 & 4 \\
\hline Groundwater levels & 4 & 312 & 2 & 1 \\
\hline
\end{tabular}

41, 29-30). The most likely date for Joseph's presence in Egypt was between 1720 and 1570 BC. (Douglas et al., 1977). Biswas (1970) reported that nilometers were used to record the fluctuation of the flows in the Nile River from about 3000 BC, so Joseph was almost certainly aware of the alternating sequences of wet and dry years when he interpreted the Pharaoh's dream.

In $641 \mathrm{AD}$ - more than a thousand years ago - a permanent water-level gauging structure was built on Rodda Island in the Nile River at Cairo. The record from the Rodda Nilometer is the longest available hydrological record. In 1950 the civil engineer RE Hurst analysed 1080 years of data recorded during the period $641 \mathrm{AD}$ to $1946 \mathrm{AD}$, in order to determine the required storage capacity of the proposed new Aswan High Dam (Hurst, 1950). He found an unexplained anomaly in the data. He then analysed other long geophysical records, where he found the same anomaly. These were sediment deposits in lakes (2 000 years), river flow (1 080 years), tree rings ( 900 years), temperature (175 years), rainfall (121 years), sunspots and wheat prices. His analyses created a great deal of interest as this anomaly has an appreciable adverse effect on the availability of water supplies from storage dams. Although the cause of the anomaly was obviously related to climatic fluctuations, the linkage was not explored.

\section{Periodicity}

Another and even more important climate-related property of the hydrometeorological processes is the presence of statistically significant 21-year periodicity in rainfall, river flow and flood peak maxima. The periodicity is non-cyclical in the trigonometrical sense, and the usage here follows the dictionary definition of observations that occur at regular intervals.

A serious drought was experienced over a large area of South Africa during the early 1970s. This resulted in the unexpected imposition of water restrictions. The problem was identified as a deficiency in the methodology used to characterise the sequential properties of annual river flow. The drought was broken by a series of severe floods later in the decade. Subsequent analyses by Alexander (1978) identified the presence of 20 -year (later 21-year) periodicity in the data, which was characterised by sequences of well-below river flow that were followed by sequences of high river flow and floods. Analyses in subsequent years confirmed the periodicity, which reached the $95 \%$ level of statistical significance in a number of rivers.

This knowledge was used to develop the first version of the prediction model described in this paper. There was another bout of severe droughts during the early 1990s, 20 years after the droughts of the 1970s (Alexander, 1995b) in which it was predicted that the drought would be broken by imminent, severe, widespread floods. Some of the worst floods on record in Southern Africa were experienced from November 1995 onwards. In December 157 lives were lost in an informal settlement outside Pietermaritzburg. This is the highest loss of life in an urban area in South Africa. Other related studies are reported in Alexander 1994; 1995a; 2002a; 2002b; 2004.

The studies reported in this paper showed that this periodicity is also present in annual rainfall and flood peak maxima. The presence of the periodicity is summarised in Table 2. The records were too short at some sites for any conclusions to be drawn.

There is also very strong evidence of a periodic pattern of prolonged droughts suddenly being broken by one or more years of abnormally high runoff. The years when these sudden reversals occurred were readily identified in the cumulative departure plots of all the data sets, other than open water surface evaporation where no periodicity was apparent.

As the degree of statistical significance is dependent on both the length of the record and the magnitude and nature of the variability about the mean, the periodicity is probably present in more sites, but has not yet reached the level of statistical significance. 


\section{Findings of other researchers}

South African climatologists were active during the period from 1970 through to 1987 when Tyson devoted a chapter in his book (Tyson, 1987) to the period of meteorological record, in which he dealt with the occurrence of wet and dry sequences in some detail.

Tyson noted that notwithstanding possible doubts that may attach to the statistical significance of a quasi 18 -year oscillation, evidence to support its physical reality was considerable in South Africa and in other countries. He provided details. He noted that the 11-year solar cycle was mentioned in the literature but he did not discuss it further.

In 2000 Bredenkamp published a comprehensive report with a section on groundwater and climate fluctuations (Bredenkamp, 2000). He used the cumulative departure method as his principal tool, for which he developed a mathematical relationship.

He demonstrated the presence of wet and dry sequences from 1919 through to 1992 based on water-level observations at Lake Mzingazi; discharge from the Uitenhage springs corrected for abstractions; water levels at Lake St Lucia; and groundwater levels at the Wondergat sinkhole in a large dolomitic formation. These all had high storage/input ratios that smooth out the shortterm fluctuations.

\section{Amalgamation of periodic sequences}

It was now possible to combine the observations by Tyson, Bredenkamp and Alexander in one table and relate the results to the grouping of wet and dry sequences and the observed periodicity.

The existence of regular, predictable climate reversals, where severe floods break sequences of drought years is beyond doubt. Their occurrence can be predicted with a high degree of accuracy (Alexander, 1995b). Similar concurrent characteristics are present in many rainfall, river flow and flood maxima series.

The periodic sequences were amalgamated and then analysed. For each process, data for each station were sequentially numbered from 1 to 21 starting with the year in which the reversals occurred, i.e. starting in 1912, 1933, 1954, 1974 and 1995. These sequence numbers are shown in the $3^{\text {rd }}$ column of Table 4.

Table 4 is a combination of the independent observations by Tyson, Bredenkamp and Alexander, each using different processes and different analytical methodologies. The right-hand column of the table shows the years in which the reversals occurred based on these studies.

The $4^{\text {th }}$ and $5^{\text {th }}$ columns show the alternating wet and dry sequences. Note how the periods between the reversals each consist of a wet sequence followed by a dry sequence. There is also a good correspondence between the dates of the sequences reported by Bredenkamp and Tyson in the first column, as well as between the first and last columns considering the different data sets and methodologies used by the two authors. These are well within the range of achievable accuracy in most hydrometeorological estimates.

Compare the lengths of the sequences in the $4^{\text {th }}$ and $5^{\text {th }}$ columns with the biblical 7 years of plenty followed by 7 years of famine. The interpretation is that these sequences and their cause have been present for thousands of years.

Many of the anomalies in the hydrometeorological processes that have been attributed to climate change are the consequence of regular, predictable, climate-related changes in these processes identified in Table 4.

\begin{tabular}{|l|c|c|c|c|c|}
\hline \multicolumn{7}{|c|}{ TABLE 4 } \\
\hline Years & $\begin{array}{c}\text { Wet/ } \\
\text { dry }\end{array}$ & $\begin{array}{c}\text { Periodic } \\
\text { sequence } \\
\text { number }\end{array}$ & $\begin{array}{c}\text { Length of } \\
\text { sequence }\end{array}$ & $\begin{array}{c}\text { Re- } \\
\text { versals }\end{array}$ \\
\cline { 3 - 5 } & Wet & Dry & \\
\hline $\begin{array}{l}\text { Bredenkamp: Mzimgazi + St Lucia + Uitenhage + Won- } \\
\text { dergat }\end{array}$ \\
\hline $1919-24$ & Wet & 08 to 13 & 5 & & \\
\hline $25-29$ & Dry & 14 to 18 & & 4 & 1933 \\
\hline $30-39$ & Wet & 19 to 07 & 9 & & \\
\hline $41-53$ & Dry & 09 to 21 & & 12 & 1954 \\
\hline $55-62$ & Wet & 02 to 09 & 7 & & \\
\hline $65-71$ & Dry & 12 to 18 & & 6 & 1974 \\
\hline $72-78$ & Wet & 19 to 05 & 6 & & \\
\hline $80-83$ & Dry & 07 to 10 & & 3 & \\
\hline $84-90$ & Wet & 11 to 19 & 6 & & 1995 \\
\hline Tyson: South African rainfall & & \\
\hline $1905-15$ & Dry & 15 to 04 & & 10 & 1912 \\
\hline $16-24$ & Wet & 05 to 13 & 8 & & \\
\hline $25-32$ & Dry & 14 to 21 & & 7 & 1933 \\
\hline $33-43$ & Wet & 01 to 11 & 10 & & \\
\hline $44-52$ & Dry & 12 to 20 & & 8 & 1954 \\
\hline $53-61$ & Wet & 21 to 08 & 8 & & \\
\hline $62-70$ & Dry & 09 to 17 & & 8 & 1974 \\
\hline $71-80$ & Wet & 18 to 07 & 9 & & \\
\hline
\end{tabular}

\section{Linkage with solar activity}

The linkage between solar activity and the annual flows in the Vaal River is immediately apparent in Fig. 1.

Starting with the sunspot graph in Fig. 1, the top panel is the conventional dimensionless histogram, where all values are expressed as multiples of the record mean values. The 21-year periodicity is apparent. A reference datum value of -200 was used in order to accommodate the negative values. This has no effect on the interpretations.

The most informative graphical presentation is in the second panel, which shows the accumulated departures from the record mean value. These are obtained by subtracting the mean values (1.0) from each of the values in the histogram. Some of the values will be negative. These are accumulated one at a time and the sum plotted.

An increase in the accumulated departures of the sunspot numbers during the period of record is immediately apparent. This is in accordance with observations of an increase in solar activity during the past century as shown by the increases in sunspot density during this period. The maximum negative departures occur at the start of the 21-year periods, identified as (A), (C), (E) and (G).

The third panel is the correlogram. This is a standard calculation procedure in time series analyses. The statistically significant cyclicity is clearly apparent. The $95 \%$ confidence limits are \pm 0.22 . The minimum and maximum $(\mathrm{H})$ autocorrelation coefficients occur respectively at $10(-0.83)$ and $21(+0.70)$ years, which are well in excess of the $95 \%$ confidence limits.

Comparing the annual flows in the Vaal River with the sunspot density characteristics, the histogram shows the high degree of asymmetry about the mean value with many more values less than the mean value than above it. This is typical of river flow data in dry climates. 


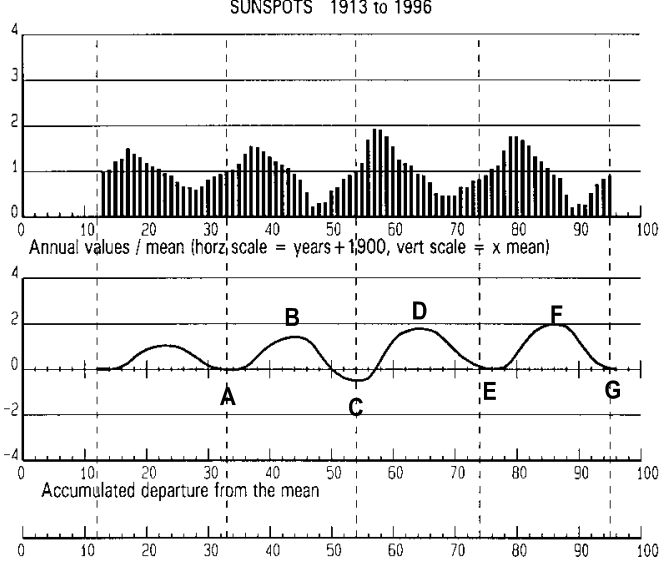

Observed periodicity - years beginning Oct. 1912, 1933, 1954, 1974, 1995

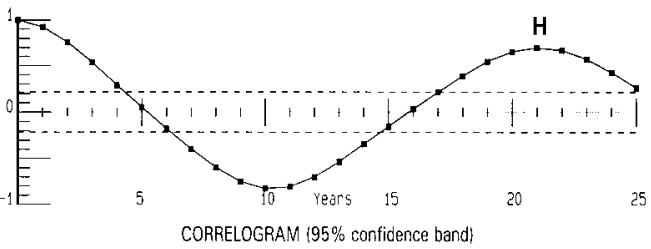

INFLOW: Vaal Dam + Grcotdraai 1923 to 1996

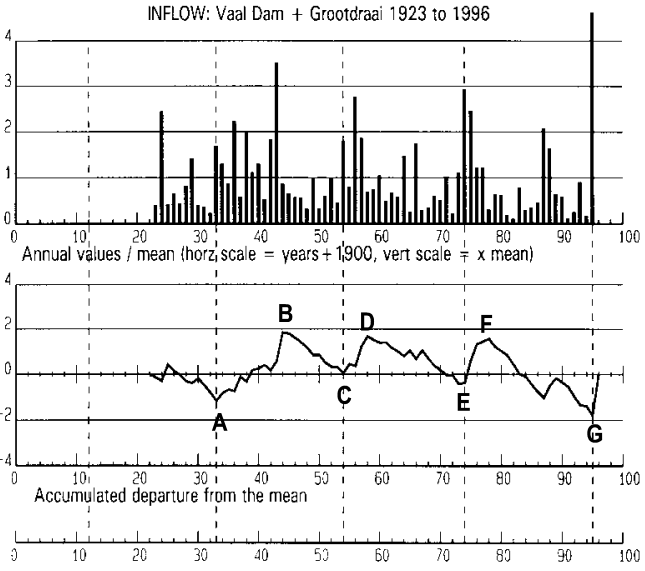

Observed periodicity - years beginning Oct. 1912, 1933, 1954, 1974, 1995

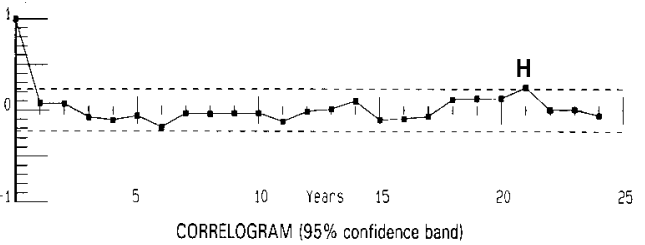

The accumulated departure plot and its comparison with that of the double sunspot cycle are very instructive. The reversals at points $(A),(C),(E)$ and $(G)$ are virtually identical with the corresponding reversals in the sunspot data. They occurred during the hydrological years beginning October 1933, 1954, 1974, and 1995. The rising limbs A-B, C-D and E-F are sequences of years where the inflows were greater than the mean value. The falling limbs B-C, D-E, and F-G are sequences where the inflows were less than the mean value. These alternating sequences are well known in the hydrological literature where they are referred to as the Joseph effect, after Joseph's biblical prophecy.

The statistically significant cyclicity in the sunspot cycles is no longer present in the correlogram of the annual flows in the Vaal River, where the residual coefficients indicate random noise. The only, but very important, residual serial correlation, is the statistically significant 21 -year periodicity. This is identified at $(\mathrm{H})$ in the bottom panel of the figure.

\section{The development of the climate prediction model}

All processes in the natural atmospheric, oceanic and terrestrial environments have a mixture of deterministic and probabilistic components, and as a result all predictions have a margin of uncertainty about them. In the absence of any other information, the best estimate of future annual values is the record mean or the median where the data are asymmetrically distributed about the mean. A basic issue in water resource planning is whether the mean is sufficiently stable for this assumption to hold during the economic lifetime of the project.

The regular grouping of alternate sequences of wet and dry years and its linkage with the 21-year periodicity is beyond doubt. The next issue was the determination of the shape of these deviations from the record mean values. More than 100 years ago Hutchins (1889) wrote: "The yellow line rising steeply to a maximum and then falling away gradually to a minimum is the sunspot curve - a curve which ought to be graven on the mind of every man and woman in South Africa."

An important characteristic of the periodicity is that the most extreme conditions occur at the beginning of the periods (floods) and at the end of the periods (droughts) with sudden reversals from droughts to floods at the end of the periods.

At this stage it must be emphasised that statistical significance tests are very poor exploratory tools in this situation and that the results of their application can be misleading. The emphasis had to continue to be on simple arithmetic and graphical analyses of the raw data. A new data set was compiled from geographically representative sites that were selected for each of the four principal hydrometeorological processes based on visual analyses of the original graphical presentations. The resultant data set consisted of open-water surface evaporation (20 stations, 1176 years); district rainfall (13 districts, 1014 years); river flow (14 stations, 1035 years); and annual flood peak maxima (11 stations, 881 years). In all, time series data for 58 stations were analysed totalling 3106 years of data.

The analyses for each process were carried out separately. For a particular process, the mean values for each station were determined and all the annual values were expressed as percentages of the record mean for the station. This was repeated for the other stations.

Thereafter, the percentage values for each station were sequentially numbered starting with the climate reversals that occurred in 1912, 1933, 1954, 1974 and 1995. For example, all observations that were made in 1950 were associated with the $18^{\text {th }}$ sequence that started in 1933, and were grouped together with the $18^{\text {th }}$ sequences in the other periods and stations. This provided 21 combined data sequences. These were the prediction model parameters.

Figure 2 shows the periodic characteristics of the annual flows in selected South African rivers. The double sunspot cycle is diagrammatically superimposed.

While there is a large scatter in the plotted results, the general trend is clear and several conclusions can be drawn from it. Major flood events are associated with the first half of the first sunspot cycle, $(\mathrm{J}-\mathrm{K})$. This is the sub-period when the rate of increase in sunspot density is greatest, and is associated with global atmospheric and oceanic turbulence at this time. This in turn generates the processes that produce heavy, widespread rainfall 


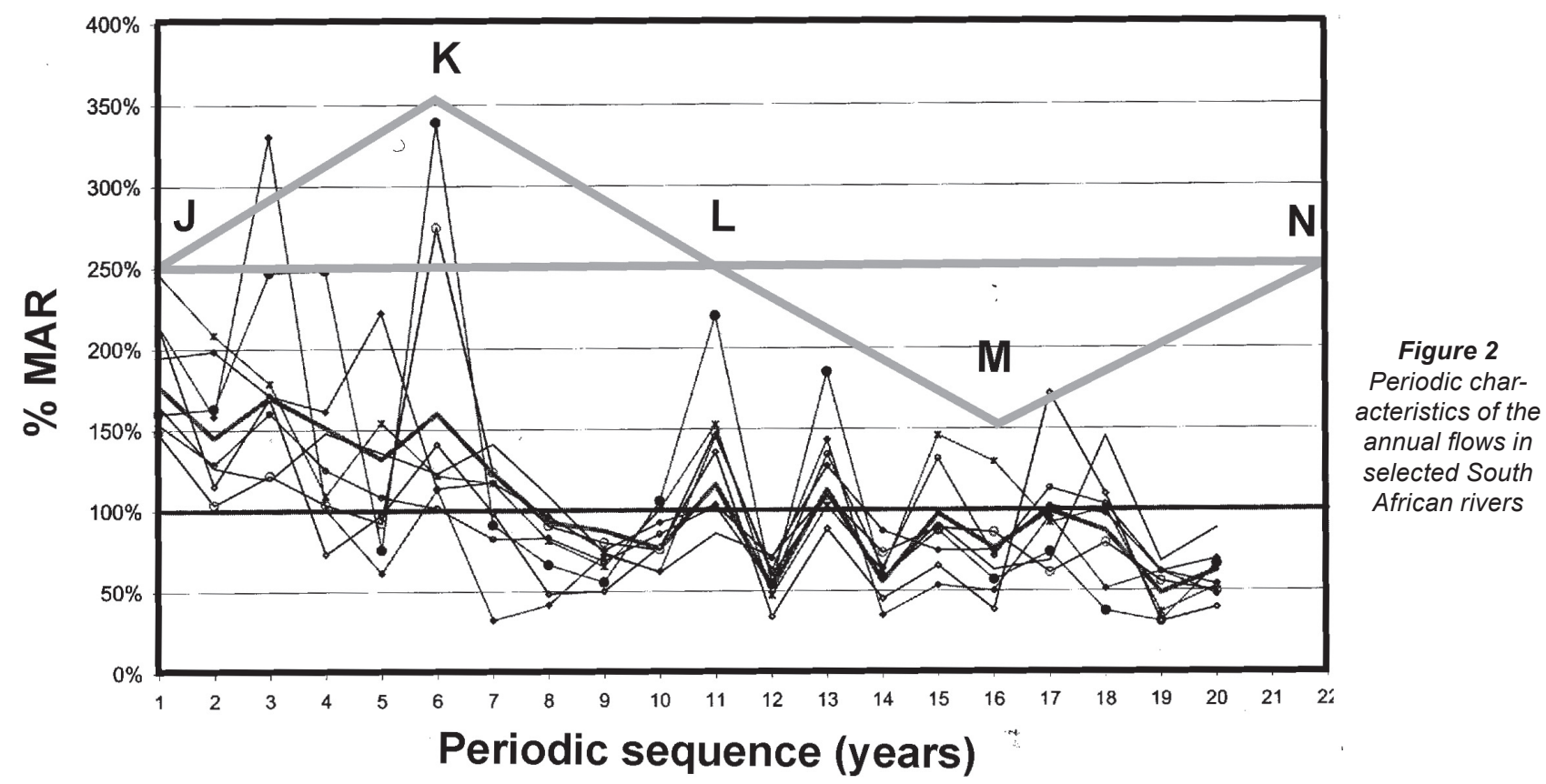

\begin{tabular}{|c|c|c|c|c|c|c|c|}
\hline \multicolumn{8}{|c|}{$\begin{array}{c}\text { TABLE } 5 \\
\text { Regional prediction model parameters for South African rainfall in the } \\
\text { summer rainfall region expressed as percentages of the mean annual } \\
\text { rainfall }\end{array}$} \\
\hline \multirow{2}{*}{$\begin{array}{l}\text { Seq } \\
\text { No }\end{array}$} & \multirow{2}{*}{$\begin{array}{l}\text { Year } \\
\text { starting } \\
\text { October }\end{array}$} & \multicolumn{6}{|c|}{ Quartiles } \\
\hline & & $\min$ & $q 1$ & median & q3 & Max & Mean \\
\hline 1 & 1995 & 71 & 97 & 117 & 140 & 189 & 118 \\
\hline 2 & 1996 & 66 & 111 & 128 & 146 & 277 & 131 \\
\hline 3 & 1997 & 49 & 82 & 100 & 132 & 173 & 103 \\
\hline 4 & 1998 & 48 & 73 & 90 & 108 & 149 & 91 \\
\hline 5 & 1999 & 61 & 80 & 92 & 104 & 146 & 92 \\
\hline 6 & 2000 & 37 & 66 & 99 & 127 & 150 & 96 \\
\hline 7 & 2001 & 70 & 102 & 128 & 154 & 268 & 130 \\
\hline 8 & 2002 & 47 & 70 & 81 & 110 & 179 & 89 \\
\hline 9 & 2003 & 34 & 76 & 84 & 102 & 150 & 88 \\
\hline 10 & 2004 & 41 & 74 & 91 & 107 & 150 & 91 \\
\hline 11 & 2005 & 46 & 82 & 99 & 116 & 150 & 98 \\
\hline 12 & 2006 & 31 & 66 & 78 & 97 & 173 & 85 \\
\hline 13 & 2007 & 41 & 92 & 103 & 127 & 191 & 109 \\
\hline 14 & 2008 & 25 & 59 & 73 & 87 & 143 & 75 \\
\hline 15 & 2009 & 25 & 74 & 89 & 104 & 140 & 87 \\
\hline 16 & 2010 & 27 & 66 & 84 & 101 & 137 & 82 \\
\hline 17 & 2011 & 51 & 86 & 101 & 114 & 165 & 102 \\
\hline 18 & 2012 & 46 & 70 & 88 & 105 & 151 & 90 \\
\hline 19 & 2013 & 60 & 77 & 87 & 96 & 130 & 87 \\
\hline 20 & 2014 & 51 & 86 & 113 & 127 & 295 & 114 \\
\hline 21 & 2015 & 29 & 72 & 92 & 123 & 194 & 99 \\
\hline 1 & 2016 & \multicolumn{6}{|c|}{ (Next reversal) } \\
\hline
\end{tabular}

river flow. Droughts occur as a result of the absence of these events.

The characteristics of the second of the two sunspot cycles (L-M-N) are very different from those of the first cycle ( $\mathrm{J}$ $\mathrm{K}-\mathrm{L})$. Fewer heavy rainfall events occur. Droughts become increasingly prevalent during this cycle. It is postulated that this is the consequence of the differences in solar magnetic polarity between the two cycles as well as the lesser sunspot density.

There is also a clear, diminishing, annual oscillatory pattern during the beginning of the second sunspot cycle that is not present in the greater scatter during the first cycle. No possible causes can be offered.

Having identified and isolated these properties, statistical analyses were carried out to determine the distribution parameters for three different statistical distribution functions. These were the conventional moments for the normal and log-Pearson type 3 distributions, and the probability weighted moments for the generalized extreme value distribution. They can be used to develop synthetic sequences using Monte Carlo procedures.

Conventional box plots can be constructed from the information in Tables 5,6 and 7. They will provide a visual in-

events that generate river flow.

In contrast, sunspot density decreases during the second half of the first cycle (K-L). This is a quiescent sub-period with reduced turbulence in the pole-ward energy distribution process, and consequent absence of high rainfall events that generate terpretation that is more illustrative than the numerical information in the tables.

These models were one of the end results of two years of intensive study of the largest and most comprehensive hydrometeorological data set yet assembled in South Africa. 


\section{Interpretation}

If the concern is agricultural droughts, then running means with durations of 2 to 4 years are more instructive than the annual values in isolation. Durations in the range from 3 to 7 years will be more instructive in the case of hydrological droughts. The individual years should therefore be considered in relation to previous and successive years and not in isolation.

Table 6 is used as an example for the interpretation of the models. It is a regional general river flow prediction model based on the analyses of a number of geographically representative gauging sites within the summer rainfall region of South Africa. It can be applied with caution at specific sites or river catchments for planning purposes, but not for specific predictions. It is a considerable improvement on current water resource planning models and the non-existent long-range climate prediction models.

The median values are the most likely values for each sequence. The predicted values have a fairly wide range of variability about the median values. Roughly $50 \%$ of the expected values for a particular year will lie within the upper and lower quartile values ( $\mathrm{q} 3$ to $\mathrm{q} 1$ ) in the table, and there is a $50 \%$ likelihood of the values being outside this range (25\% above and $25 \%$ below). The minimum values are also of interest as they show that exceptionally low values have been observed during all sequences.

The severity of a drought increases rapidly with its duration. Soil moisture varies with rainfall. At the commencement of a drought the soil moisture becomes progressively depleted and vegetation and crops come under increasing stress. Eventually, rivers stop flowing. It requires above-average rainfall to restore the soil moisture levels before surface runoff and river flow can recommence.

It is also important to appreciate that over most of South Africa the storage dam capacities are well in excess of the mean annual river flow. Consequently, as the volumes in storage are depleted, it will require inflows of well in excess of the mean annual river flow to replenish the storage while at the same time continuing to meet the demand from them. However, the average of the maximum observed values for the first 10 years of the model is $675 \%$ of the record mean values, while the corresponding aver-
TABLE 6

Regional prediction model parameters for South African rivers in the summer rainfall region expressed as percentages of the mean annual river flow

\begin{tabular}{|c|c|c|c|c|c|c|c|}
\hline \multirow{2}{*}{$\begin{array}{l}\text { Seq } \\
\text { No }\end{array}$} & \multirow{2}{*}{$\begin{array}{c}\text { Year } \\
\text { starting } \\
\text { October }\end{array}$} & \multicolumn{6}{|c|}{ Quartiles } \\
\hline & & $\min$ & q1 & median & q3 & Max & mean \\
\hline 1 & 1995 & 19 & 83 & 135 & 282 & 1351 & 218 \\
\hline 2 & 1996 & 3 & 81 & 127 & 225 & 423 & 147 \\
\hline 3 & 1997 & 2 & 70 & 136 & 221 & 490 & 150 \\
\hline 4 & 1998 & 6 & 61 & 81 & 117 & 593 & 120 \\
\hline 5 & 1999 & 3 & 63 & 99 & 204 & 1181 & 157 \\
\hline 6 & 2000 & 14 & 72 & 100 & 160 & 668 & 124 \\
\hline 7 & 2001 & 11 & 40 & 75 & 91 & 224 & 77 \\
\hline 8 & 2002 & 6 & 42 & 65 & 104 & 421 & 75 \\
\hline 9 & 2003 & 5 & 44 & 82 & 163 & 756 & 111 \\
\hline 10 & 2004 & 12 & 52 & 90 & 193 & 645 & 138 \\
\hline 11 & 2005 & 13 & 37 & 54 & 82 & 239 & 65 \\
\hline 12 & 2006 & 18 & 70 & 124 & 196 & 565 & 138 \\
\hline 13 & 2007 & 9 & 41 & 61 & 88 & 470 & 87 \\
\hline 14 & 2008 & 3 & 54 & 74 & 131 & 501 & 98 \\
\hline 15 & 2009 & 9 & 28 & 57 & 81 & 170 & 63 \\
\hline 16 & 2010 & 3 & 61 & 86 & 129 & 353 & 102 \\
\hline 17 & 2011 & 11 & 51 & 96 & 123 & 279 & 95 \\
\hline 18 & 2012 & 2 & 27 & 52 & 83 & 217 & 59 \\
\hline 19 & 2013 & 6 & 57 & 92 & 161 & 445 & 115 \\
\hline 20 & 2014 & 9 & 30 & 62 & 140 & 562 & 118 \\
\hline 21 & 2015 & 20 & 99 & 155 & 229 & 892 & 201 \\
\hline 1 & 2016 & & & (Next & ersal) & & \\
\hline
\end{tabular}

\begin{tabular}{|c|c|c|c|c|c|c|c|}
\hline \multicolumn{8}{|c|}{$\begin{array}{c}\text { TABLE } 7 \\
\text { Regional prediction model parameters for South African flood peak } \\
\text { maxima expressed as percentages of the mean annual values }\end{array}$} \\
\hline \multirow{2}{*}{$\begin{array}{l}\text { Seq } \\
\text { No }\end{array}$} & \multirow{2}{*}{$\begin{array}{l}\text { Year } \\
\text { starting } \\
\text { October }\end{array}$} & \multicolumn{6}{|c|}{ Quartiles } \\
\hline & & $\min$ & q1 & median & q3 & $\max$ & mean \\
\hline 1 & 1995 & 5 & 64 & 96 & 280 & 1148 & 266 \\
\hline 2 & 1996 & 9 & 59 & 103 & 210 & 1463 & 182 \\
\hline 3 & 1997 & 1 & 54 & 86 & 272 & 945 & 176 \\
\hline 4 & 1998 & 1 & 54 & 84 & 150 & 1027 & 183 \\
\hline 5 & 1999 & 3 & 48 & 68 & 222 & 621 & 130 \\
\hline 6 & 2000 & 6 & 42 & 100 & 135 & 499 & 110 \\
\hline 7 & 2001 & 4 & 31 & 61 & 97 & 241 & 75 \\
\hline 8 & 2002 & 3 & 30 & 63 & 117 & 551 & 99 \\
\hline 9 & 2003 & 2 & 30 & 61 & 148 & 780 & 139 \\
\hline 10 & 2004 & 1 & 52 & 99 & 231 & 905 & 178 \\
\hline 11 & 2005 & 1 & 35 & 61 & 102 & 335 & 77 \\
\hline 12 & 2006 & 1 & 41 & 106 & 254 & 731 & 146 \\
\hline 13 & 2007 & 6 & 28 & 52 & 132 & 337 & 85 \\
\hline 14 & 2008 & 2 & 31 & 56 & 126 & 269 & 78 \\
\hline 15 & 2009 & 1 & 38 & 63 & 125 & 539 & 103 \\
\hline 16 & 2010 & 1 & 34 & 82 & 130 & 432 & 101 \\
\hline 17 & 2011 & 1 & 28 & 60 & 157 & 890 & 124 \\
\hline 18 & 2012 & 2 & 25 & 45 & 97 & 602 & 83 \\
\hline 19 & 2013 & 1 & 37 & 101 & 167 & 465 & 130 \\
\hline 20 & 2014 & 1 & 31 & 56 & 132 & 928 & 121 \\
\hline 21 & 2015 & 17 & 79 & 148 & 244 & 499 & 171 \\
\hline 1 & 2016 & \multicolumn{6}{|c|}{ (Next reversal) } \\
\hline
\end{tabular}


age for the following 10 years is only $380 \%$ of the record mean values. This results in the observed wet and dry sequences and has serious consequences. Not only are the river flows appreciably less during the latter half of the period, but the higher flows required to reduce the effect of the drought and to fill the dams are also less than during the earlier half of the period. Table 6 should be interpreted with these factors in mind.

The period begins with the reversal associated with the floods that broke the previous drought. This occurred during the hydrological year beginning October 1995. During the first 6 years of the sequence (1995 to 2000) the median values exceed or are close to the record mean values shown in the right-hand column of the table. Widespread floods can be expected during this period and dam storages will be in a healthy state.

The possibility of droughts increases dramatically during the following five years (2001 to 2005). River flows are likely to be well below the record mean values and droughts are increasingly likely. Dam storages will decrease and the threat of water restrictions will increase.

However, there is an increasing probability of higher river flows that mark the end of the first half-period and its probable relationship with increased solar activity. It lasts through to the $11^{\text {th }}$ year (2006) when some relief can be expected. This is the first half of the double sunspot cycle that has long been observed. It confirms Hutchins' 100-year old predictions.

The next half-period is that associated with the famines observed in ancient Egypt and reported in India during the 1800s. The subsequent 7-year period (note the similarity with the biblical 7 years) will be critical for the water supply situation in South Africa with frequent years of well-below average flows, and steadily decreasing high inflows to compensate for them. The imposition of water restrictions over large parts of South Africa will be almost inevitable. The next reversal is due within a year or two of 2016.

\section{Confirmation}

In 1995 Alexander stated that "The acid test that will demonstrate whether or not the 20-year periodicity continues is at hand. If the drought is broken by widespread rainfall during the next two years it will surely be conclusive". The paper was published in August 1995 (Alexander ,1995b). Four months after publication, severe floods occurred over a wide area of Southern Africa. Hundreds of lives were lost and the drought was broken.

The high rainfalls continued and the widespread 1999 to 2000 regional floods caused considerable damage and loss of life including the severe floods in Mozambique. Although these floods were at their maximum during January and February 2000 , the maximum countrywide monthly rainfall occurred during the previous month. It was the widespread earlier rains that saturated the soils and filled the rivers.

Serious droughts over Southern Africa commenced during the summer of 2001 to 2002, the $7^{\text {th }}$ year of the sequence. In the present hydrological year beginning October 2004 we are in the $10^{\text {th }}$ year of the sequence and $4^{\text {th }}$ successive year of below-normal flows. At the time of writing the position in the central interior of Southern Africa is critical. Drought relief measures are still in place in Botswana and will continue until June 2005 at least. Water restrictions have been imposed in the Cape Town metropolitan area. Drought relief aid has been provided for farmers over a wide region.

\section{Reliability of the predictions}

The situation in South Africa for the first 9 years after the 1995 reversal was in accordance with the climate prediction model, which lends strong support to the validity of the model.

This periodicity and its association with wet and dry sequences is extremely important for all those who maintain that global warming will result in increased variability in the hydrological process - specifically floods, droughts and water supplies. In order to provide convincing arguments, an accurate, numerical description of the present position will first have to be produced. Once this has been done, it will have to be demonstrated (not postulated) how global warming will change the alternating wet and dry sequences; the associated periodic properties; and the drought and flood severities. Simple statements that global warming will increase the variability in the hydrological processes, and consequently the magnitude and frequency of floods and droughts, are unacceptably naïve.

The periodicity and the alternating wet and dry sequences are also very important characteristics for those responsible for the planning and operation of major water supply projects. The current approach of assuming random variations about a nearconstant mean and the omission of regular, non-random, alternating sequences of wet and dry years is equally unrealistic.

\section{Conclusions}

This study demonstrates the increase in rainfall over South Africa during the past 78 years at least, and its probable relationship with global warming, which in turn is probably the consequence of the increase in solar activity during that period. Despite a diligent examination of a very large and comprehensive hydrometeorological database, no evidence could be found to support the claims that climate change will result in an increase in the frequency and magnitude of floods and droughts, or pose a threat to water supplies.

The study shows the presence of a statistically significant 21-year periodicity in rainfall, river flow and flood peak maxima. The periodicity is predictable and is characterised by severe droughts being broken by sudden widespread floods. The periodicity is associated with alternating sequences of wet and dry periods that have been reported since biblical times. These soundly based observations are the basis of a general climate prediction model. The model demonstrates that previously assumed climate change-related groupings of years with unusually high or low characteristics are not the result of climate change but are natural sequences.

Perhaps most importantly, the general climate prediction model for South Africa can be built on by others to produce a more refined model in future, as well as a better numerical understanding of the linkage between atmospheric processes and hydrometeorological responses.

\section{Suggested further studies}

The periodic perturbations in the rainfall and river flow are related to solar activity - a fact that was demonstrated by Hutchins and many others more than 100 years ago. There is a lot of evidence that can be extracted from the vast amount of hydrometeorological data that can be used to provide linkages between solar activity, climatic and oceanic processes, and hydrological and meteorological responses. The following are some suggestions for further studies:

- What is the cause of the 21-year periodicity? Is it related directly to perturbations in solar activity, or is it a result of processes involved in the pole-ward transfer of solar energy, 
which is greatest in the low latitudes in which South Africa is located?

- What is the process that results in observation that the annual rainfall and river flow magnitudes rise steeply to a maximum and then fall away gradually to a minimum as noted by Hutchins more than a century ago (Hutchins, 1889), and confirmed by these analyses?

- What is the process that results in the sudden reversals from droughts to floods? It is obviously an instability phenomenon but what are the causes and triggering mechanisms?

- What is the linkage between the findings reported here and the El Niño phenomenon? This is very important as it will then enable forecasters to extend the range of their forecasts from the present to well into the future.

There are many questions that remain unanswered.

\section{References}

ABU-ZEID MA and BISWAS AK (1992) Climatic Fluctuations and Water Management. Butterworth-Heineman. 356 pp.

ALEXANDER WJR (1978) Long Range Prediction of River Flow - A Preliminary Assessment. Technical Report TR80. Department of Water Affairs, Pretoria.

ALEXANDER WJR (1994) Anomalies in the stochastic properties of river flow and their effect on reservoir yield. Proc. Republic of China-South Africa Bilateral Symposium. Taipeh, Taiwan.

ALEXANDER WJR (1995a) Detection of climate change. Proc. IGBP Conf. on Global Environmental Change - Implications for Southern Africa. Pretoria

ALEXANDER WJR (1995b) Floods, droughts and climate change. S. Afr. J. Sci. 91 403-408

ALEXANDER WJR (2001) Flood Risk Reduction Measures. Department of Civil Engineering, University of Pretoria, $560 \mathrm{pp}$.

ALEXANDER WJR (2002a) Climate change - The missing links. Sci. in Afr.. September 2002.

ALEXANDER WJR (2002 b) Statistical analysis of extreme floods. J. S. Afr. Inst. Civ. Eng. 44 (1) 2002 20-25.
ALEXANDER WJR (2004) Climate change - there is no need for concern. Going against the flow. Sci. in Afr. (April).

BASSON MS, ALLEN RB, PEGRAM GGS AND VAN ROOYEN JA (1994) Probabilistic Management of Water Resource and Hydropower Systems. Water Resource Publications, Colorado, USA.

BISWAS AK (1970) History of Hydrology. North-Holland Publishing Company, Amsterdam. 336 pp.

BREDENKAMP DB (2000) Groundwater Monitoring: A Critical Evaluation of Groundwater Monitoring in Water Resources Evaluation and Management. Water Research Commission Report No. 838/1/00.

DOUGLAS JD, BRUCE FF, TASKER RVG, PACKER JJ and WISEMAN DJ (1977) The New Bible Dictionary. Intervarsity Press. London.

FANTECHI G, MARACCHI ME and ALMEIDA-TEIXEIRA ME (1991) Climate Change and Impacts: A General Introduction. Commission of the European Communities, EUR 11943. 453 pp.

GLEICK PH (2000) Water: The Potential Consequences of Climate Variability and Change for the Water Resources of the United States. US Department of the Interior.

HURST RE (1950) Long-term storage capacity of reservoirs. Trans. of the Am. Soc. of Civ. Eng. Paper 2447.

HUTCHINS DE (1889) Cycles of Drought and Good Seasons in South Africa. Wynberg Times Steam Printing Office. Wynberg

INTERGOVERNMENTAL PANEL ON CLIMATE CHANGE (2001) Summary for Policymakers.

PAOLI G (ed.) (1994) Climate Change, Uncertainty and Decision making. Institute for Risk Research, Waterloo, Canada. $165 \mathrm{pp}$.

TYSON PD (1987) Climatic Change and Variability in Southern Africa. Oxford University Press. $220 \mathrm{pp}$.

TYSON PD and GATEBE CK (2001) The atmosphere, aerosols, trace gasses and biochemical change in southern Africa: A regional integration. S. Afr. J. Sci. 97 106-118.

WEATHER BUREAU, now SOUTH AFRICAN WEATHER SERVICES (1972) Climate of South Africa: Part 10, District Rainfall and the Annual March of Rainfall over Southern Africa. WB 35, Pretoria 
